\title{
AÇÕES FORMATIVAS EM DISCIPLINAS DE PRÁTICA PEDAGÓGICA NA LICENCIATURA EM EDUCAÇÃO FÍSICA
}

\author{
Willer Soares Maffei' \\ Roseli Pacheco Schetzler ${ }^{2}$
}

\section{RESUMO}

Neste trabalho, são investigadas contribuições para a docência inicial decorrentes de três ações formativas desenvolvidas em duas disciplinas de Prática Pedagógica nos dois últimos semestres de um curso de licenciatura noturno em Educação Física. Neste sentido, são articuladas ações pautadas na formação do professor reflexivo, em modelos de ensino fundamentados na cultura corporal de movimento e na orientação, problematização e reformulação de planos de ensino a serem desenvolvidos no Estágio Supervisionado por quinze futuros professores. Depoimentos dos mesmos, obtidos por meio de entrevistas gravadas e transcritas, segundo uma abordagem qualitativa de pesquisa, evidenciam a importância de tais ações que, por se contraporem ao modelo formativo vigente - racionalidade técnica, que enfatiza uma concepção de Educação Física como atividade técnica, desportiva e descompromissada de seus propósitos educacionais - configuram-se como propostas significativas para uma melhor formação docente inicial naquela área.

Palavras-chave: Licenciatura em educação física. Formação do professor reflexivo. Cultura corporal de movimento

1 Doutor em Educação. Professor Assistente do Departamento de Educação Física da Universidade Estadual Paulista (UNESP). Bauru/São Paulo, Brasil. E-mail: willermaffei@fc.unesp.br

2 Doutora em Educação Química. Professora Titular da Universidade Metodista de Piracicaba (UNIMEP). Piracicaba/São Paulo, Brasil. E-mail: roseschnet@superig.com.br 


\title{
TRAINING IN PEDAGOGICAL PRACTICE IN A PHYSICAL EDUCATION DEGREE COURSE
}

\begin{abstract}
This article discusses the contributions to initial teaching resulting from three formative actions developed in two Pedagogical Practice subjects in the last two semesters of an evening degree course in Physical Education. To this end, actions for training reflective teachers are linked with teaching models based on the body movement culture as well as training, questioning and reformulating teaching plans to be used in supervised student teaching by fifteen future teachers. Statements from these future teachers, obtained through recorded interviews and transcribed according to a qualitative research approach, demonstrate the importance of such activities. By opposing the current training model of technical rationality that emphasizes the concept of physical education as a technical and sporting activity which is not committed to educational purposes, these activities present themselves as significant alternatives for the initial training of teachers in this area.
\end{abstract}

Keywords: Degree in physical education. Training a reflective teacher. Body movement culture

\section{ENTRENAMIENTO EN PRÁCTICA PEDAGÓGICA EN UN CURSO DE GRADO DE EDUCACIÓN FÍSICA}

\section{RESUMEN}

En este artículo son analizadas las aportaciones a la enseñanza inicial resultantes de tres acciones formativas desarrolladas en dos asignaturas de la Práctica Pedagógica en los dos últimos semestres de un curso nocturno de Educación Física. En este sentido, son articuladas acciones guiadas por la formación reflexiva, en modelos de enseñanza basados en la Cultura Corporal del Movimiento, así como la formación, cuestionamiento y reformulación de los planes de enseñanza utilizados en la Docencia Supervisada por quince futuros maestros. Las declaraciones de estos, obtenidas por medio de encuestas grabadas y transcritas según un enfoque de investigación cualitativa, demuestran la importancia de estas acciones, al oponerse al modelo actual de formación - racionalidad técnica, que hace hincapié en el concepto de Educación Física como actividad técnica, deportiva y no comprometida con propósitos educacionales - estas actividades se presentan como alternativas significativas para la formación inicial de los maestros en aquella área.

Palabras clave: Licenciatura en educación física. Formación del maestro reflexivo. Cultura corporal del movimiento 


\section{INTRODUÇÃO}

Vários educadores vêm apontando a ineficiência do modelo de formação docente pautado na racionalidade técnica por este enfatizar a dicotomia teoria-prática, afastando a universidade da escola, a resolução de problemas profissionais pela mera aplicação de teorias e métodos previamente apreendidos, ignorando a complexidade, a incerteza e a singularidade dos processos educacionais e, principalmente, por conceber o professor como um simples técnico, ao qual cabe cumprir determinações propostas e, muitas vezes, impostas por agentes externos ao ambiente escolar, sejam eles políticos, gestores ou pesquisadores educacionais (SCHÖN, 1992; ZEICHNER, 1993; PÉREZ-GÓMEZ, 1992; NÓVOA, 1992; PIMENTA, 2001).

Apesar dessas críticas, tal modelo ainda se mantém presente na maioria dos cursos de licenciatura em nossas instituições de ensino superior, impondo a necessidade de miná-lo internamente, pois, conforme SCHNETZLER (2002) afirma, ao analisar a licenciatura em Química:

(...) uma forte razão apontada pela literatura revela que potenciais contribuições da pesquisa educacional não chegam às salas de aula de forma significativa porque, usualmente, os professores, em seus processos de formação inicial (cursos de licenciatura) e continuada não têm sido introduzidos à pesquisa educacional. Por isso, tendem a ignorá-la, descompromissando-se de investigar a própria prática pedagógica para melhorá-la. (...) Entretanto, a literatura também revela que o processo de mudança paradigmática, visando romper, gradativamente, com o modelo da racionalidade técnica, implica em ações que o minem por dentro. Isso significa catalisar mudanças no processo de formação docente, mesmo dentro de um contexto marcado pelos ditames daquela racionalidade. Sem enfrentar a necessidade de meIhorar a formação docente em química, seja ela inicial ou continuada, dificilmente conseguiremos que contribuições de pesquisas sejam, de fato, concretizadas e produzidas na maioria das salas de aula de química de nossas escolas. (SCHNETZLER, 2002, p.22).

Assim, é dentro deste propósito de contribuir para minar gradativamente o modelo da racionalidade técnica na formação docente em Educação Física que propusemos e desenvolvemos as ações formativas aqui descritas. Outra razão que as apóia é a de procurar conferir a devida importância às disciplinas de Prática Pedagógica - componente proposto pelas Diretrizes Curriculares para os Cursos de Licenciatura, num total de 400 horas, além das 400 horas previstas de Estágio Supervisionado - ao articulá-las a este último, propósito nem sempre atingido e compreendido pelos coordenadores de tais cursos.

Nesse contexto é que se situam críticas e sugestões dirigidas aos cursos de licenciatura. Pimenta (2001, p. 39) assinala "a distância entre a formação e a atuação profissional, uma vez que os conhecimentos tratados nos cursos de formação de professores não contemplam a realidade prática encontrada nas escolas". Como alternativa à superação da relação linear e mecânica entre o conhecimento científico e a prática na sala de aula, são propostos currículos que enfatizem a prática profissional e que se apresentem como uma 
forma de imersão no mundo da experiência docente por meio da reflexão e da investigação sobre as próprias ações, levando o futuro professor à interpretação da realidade na busca de reorganizar a sua própria experiência. Para Yinger (apud Pérez-Gómez, 1992, p.102), "o êxito do profissional depende de sua capacidade para manejar a complexidade e resolver problemas práticos, através da integração inteligente e criativa do conhecimento e da técnica". Marcelo (1992, p. 52) "destaca o valor da prática como elemento de análise e reflexão do professor".

Desta forma, o atual contexto da melhoria da formação de professores sugere uma sinergia da investigação com a reflexão sobre ações da profissão que deve acompanhar o processo de formação e atuação do profissional. Nesse sentido, no processo de formação docente inicial, o componente curricular da Prática Pedagógica se apresenta como um momento importante pela promoção de relações entre conhecimentos da formação e a futura prática profissional.

\section{Dados contextuais e metodológicos}

A investigação foi realizada em um curso noturno de Licenciatura em Educação Física, de um Instituto Superior de Educação privado, situado no interior do estado de São Paulo, em duas disciplinas curriculares obrigatórias, denominadas Prática Pedagógica III e IV, respectivamente desenvolvidas no quinto e sexto períodos do curso, isto é, em seu último ano.

Dentre outros objetivos, esses componentes curriculares pautam-se na elaboração de planos de ensino para o desenvolvimento do estágio supervisionado; participação em grupos de estudo; discussões sobre a prática pedagógica do professor, possibilitando interligações de elementos advindos do curso de formação profissional com a atuação docente, propiciando experiências de ser professor e, ao mesmo tempo, discutindo a atuação profissional, mediações docentes e saberes profissionais do professor de Educação Física.

Realizada junto a 15 futuros professores e contando com o mesmo professor-formador nas duas disciplinas de Prática Pedagógica (autor deste trabalho), a presente investigação buscou construir possíveis respostas à seguinte questão: quais contribuições para a formação de futuros professores de Educação Física decorrem de ações formativas desenvolvidas nas disciplinas de Prática Pedagógica III e IV e que são fundamentadas na reflexão docente, na Cultura Corporal de Movimento e na orientação, problematização e replanejamento de planos de ensino?

Partindo de algumas hipóteses sobre a questão de investigação, três ações formativas e articuladas foram planejadas e desenvolvidas: $1^{\text {a }}$ ) estudos e discussões sobre o professor reflexivo junto aos licenciandos para fundamentar a necessária reflexão sobre a prática docente que iriam, posteriormente, realizar no estágio supervisionado; $2^{\mathrm{a}}$ ) planejamento e apresentação aos licenciandos de um modelo de ensino fundamentado na tematização dos elementos da Cultura Corporal de Movimento a fim de embasar a elaboração de seus planos de estágio; $3^{\mathrm{a}}$ ) orientação e problematização do planejamento e replanejamento 
de planos de ensino, via email, a serem desenvolvidos pelos futuros professores no estágio supervisionado. As duas primeiras ações formativas foram desenvolvidas na disciplina Prática Pedagógica III e na IV foi realizada a terceira ação.

Para a construção de respostas à questão de investigação aqui enfocada, a coleta de dados implicou na obtenção de depoimentos dos 15 licenciandos por meio de entrevistas realizadas no final do ano letivo, após o término da disciplina de Prática Pedagógica IV. Além disso, para cada licenciando, foi criada uma pasta digital na qual foi registrada a troca de e-mails com o professor-formador durante o período de elaboração e reelaboração do plano de ensino a ser, posteriormente, desenvolvido no estágio supervisionado, configurando a terceira ação formativa acima mencionada.

Para construir os dados referentes às pastas digitais, o professor-formador realizou várias leituras para a análise do conteúdo dos planos de ensino segundo cinco categorias que correspondem aos princípios orientadores adotados para a elaboração dos mesmos: sequência e continuidade dos conteúdos; trajetória de aprendizagem; tematização dos elementos da Cultura de Movimento; dimensões do conteúdo e relação objetivo/conteúdo, as quais são descritas na segunda ação formativa. Tal procedimento permitiu o acompanhamento individual de cada licenciando e o registro em um quadro de suas dificuldades na elaboração e reelaboração do seu plano de ensino. Os registros, por sua vez, permitiram organizar os 15 licenciandos em três grupos $(\mathrm{G} 1 ; \mathrm{G} 2 ; \mathrm{G} 3)$ de acordo com o grau crescente de dificuldade encontrado para a elaboração e correção dos planos de ensino para o estágio supervisionado.

Para a construção dos dados referentes às contribuições das ações formativas desenvolvidas pelo professor-formador, foram realizadas três entrevistas, quinze dias após a conclusão da disciplina Prática Pedagógica IV. As entrevistas foram realizadas em três noites, uma para cada grupo, gravadas em áudio e transcritas, e tiveram a duração de cerca de duas horas cada. Várias leituras das transcrições foram feitas e os depoimentos dos licenciandos foram recortados pela utilização da análise qualitativa do conteúdo de suas respostas às cinco questões que compuseram o roteiro da entrevista, a saber:

- Como vocês avaliam estes dois semestres de Práticas Pedagógicas?

- Como vocês entraram e como hoje se sentem em relação à atuação como professor, como futuro profissional de Educação Física?

- Houve alguma mudança na sua atuação como aluno/docente de Educação Física?

- Se sim, quais momentos, fatos e/ou ações são responsáveis por mudanças no seu pensamento e na sua forma de atuação como aluno/docente de Educação Física?

- O que fez vocês mudarem?

Optamos por apresentar e discutir nossos resultados para cada uma das três ações formativas desenvolvidas nas disciplinas de Prática Pedagógica III e IV, considerando depoimentos de licenciandos pertencentes aos três grupos G1; G2 e G3. Para discuti-los, recorremos aos nossos referenciais teóricos centrados no professor reflexivo e na cultura corporal de movimento. 


\section{Descrição e fundamentação das Ações Formativas}

Como mencionado anteriormente, três ações formativas foram desenvolvidas pelo professor-formador: Estudos e discussões sobre o professor reflexivo e apresentação de modelo de ensino fundamentado na Cultura Corporal de Movimento tiveram lugar na disciplina de Prática Pedagógica III, enquanto a orientação, problematização e replanejamento de planos de ensino ocorreram na Prática Pedagógica IV, junto a 15 futuros professores de Educação Física. A seguir, são descritas tais ações.

\section{$1^{\mathrm{a} A c ̧ a ̃ o ~-~ E s t u d o s ~ e ~ d i s c u s s o ̃ e s ~ s o b r e ~ o ~ p r o f e s s o r ~ r e f l e x i v o ~}$}

O objetivo desta ação foi discutir modelos de formação de professores, enfatizando a proposta do professor reflexivo. Para tal, foram realizados seminários em duplas e trios de licenciandos sobre os seguintes textos:

- PÉREZ-GÓMEZ, A. (1992) "O pensamento prático do professor: a formação do professor como profissional reflexivo". O texto foi utilizado para o entendimento dos modelos de formação pautados na racionalidade técnica e na racionalidade prática, iniciando-se a discussão com a necessidade de refletir sobre a própria prática docente;

- SCHÖN, D. (2000) "Educando o profissional reflexivo: um novo design para o ensino e a aprendizagem". Para discutir sobre a formação do professor a partir da reflexão sobre a sua própria prática;

- TARDIF, M. (2002) "Saberes docentes e formação profissional" (capítulo 1). Para que os licenciandos percebessem que não basta apenas uma prática reflexiva para a formação e atuação profissional; existem saberes relacionados à profissão que cabem ao professor desenvolver;

- ZEICHNER, K. (1993) A Formação Reflexiva de Professores: Idéias e Práticas (capítulo 1). Reforçando a formação do profissional reflexivo e trazendo atitudes necessárias para tal.

Estes seminários e discussões foram realizados em encontros quinzenais, durante três meses. À medida que tais discussões se aprofundaram, surgiu a necessidade de explicitar e, principalmente, de demonstrar novos olhares para a aula de Educação Física, diferentes daqueles restritos a técnicas e adestramentos, típicos do modelo de formação docente pautado na racionalidade técnica, aos quais os licenciandos estavam habituados. Para desconstruir tais concepções, não bastam críticas; há necessidade de demonstrar como se pode fazer diferente, e melhor! Por isso, as duas ações formativas - estudos sobre o professor reflexivo e apresentação de modelo de ensino pelo professor-formador ( $2^{\mathrm{a}}$ ação, descrita a seguir) - foram desenvolvidas paralelamente na disciplina Prática Pedagógica III, visando que os licenciandos aprendessem e vivenciassem um novo modelo de ensino, ao mesmo tempo em que refletissem sobre ele. Com isso, buscamos uma forma de levá-los à reflexão sobre o próprio plano de ensino, sobre o desenvolvimento de suas ações 
e, principalmente, sobre os resultados delas advindos nos dois estágios supervisionados que deveriam cumprir.

Considerando que a problematização é a condição primeira para a reflexão, a aplicação dos estudos sobre o professor reflexivo se fez presente na disciplina de Prática Pedagógica IV, ocasião em que os licenciandos elaboraram um segundo plano de ensino para o estágio, para os quais foi proposta a tarefa que refletissem sobre a prática desenvolvida na escola. Para tal, foi sugerido um roteiro de questões, apresentado a seguir, para que os auxiliasse nesta tarefa, adotando as atitudes, descritas por Zeichner (1993), como necessárias à ação reflexiva: i) abertura de espírito (o professor se questiona constantemente por que está fazendo o que faz na sala de aula); ii) sinceridade, e iii) responsabilidade, representada pelas consequências de uma determinada ação (como está sendo o resultado e para quem interessa).

Assim, os licenciandos foram solicitados a refletir sobre as suas práticas desenvolvidas no estágio, a escrever sobre as consequências do seu ensino e a replanejar a sua atuação docente segundo o seguinte roteiro de perguntas a serem respondidas após as aulas ministradas no estágio:

- Por que você está fazendo o que faz na aula?

Quais são os efeitos do seu ensino no auto-conceito dos seus alunos?

Quais são os efeitos do seu ensino no desenvolvimento dos seus alunos?

Quais são os efeitos do seu ensino na vida dos seus alunos?

- $\quad$ O que o (a) surpreendeu nas suas aulas? Por quê? Como você resolveu tais surpresas? Você mudaria o quê?

Justificando as duas últimas perguntas propostas aos licenciandos para suas reflexões, é importante ressaltar a importância que SCHÖN (1992) atribui ao dar razão ao aluno. Ele diz:

Existe, primeiramente, um momento de surpresa: um professor reflexivo permite-se ser surpreendido pelo que o aluno faz. Num segundo momento, reflecte sobre esse facto, ou seja, pensa sobre aquilo que o aluno disse ou fez e, simultaneamente, procura compreender a razão por que foi surpreendido. Depois, num terceiro momento, reformula o problema suscitado pela situação; talvez o aluno não seja de aprendizagem lenta, mas, pelo contrário, seja exímio no cumprimento das instruções. Num quarto momento, efectua uma experiência para testar a sua nova hipótese; por exemplo, coloca uma nova questão ou estabelece uma nova tarefa para testar a hipótese que formulou sobre o modo de pensar do aluno (SCHÖN, 1992, p.83).

\section{$2^{\mathrm{a}}$ Ação: Apresentação de um modelo de ensino}

Embora a expressão modelo possa transmitir a idéia de repetição de algo pronto, de reprodução, não é este o sentido atribuído para a ação formativa proposta. Conforme apontam Chaves (2000), Maldaner (1997) e Schnetzler (2000), mudanças na prática peda- 
gógica pressupõem a crítica a modelos tradicionais, a apresentação de um novo modelo que se quer implementar e a vivência do mesmo, em um processo concomitante de desconstrução e construção de novas concepções docentes. Além disso, Schön (2000) propõe a necessidade de apresentação de uma nova prática, por parte do formador, baseada na estratégia reflexiva denominada siga-me, a qual

(...) deve ser utilizada quando um instrutor deseja comunicar uma maneira de trabalhar, ou uma concepção de execução, que vá além de qualquer coisa que a estudante seja capaz de descrever no momento. (...) seu padrão dominante é a demonstração e a imitação, sua mensagem é 'faça como eu estou fazendo' (...) O convite à imitação é, além disso, um convite ao experimento, já que, para 'seguir' a estudante deve construir, em sua própria execução, o que ela considera as características essenciais da demonstração (p.161).

Dessa forma, o modelo de ensino ministrado pelo formador objetivou a apresentação de uma forma de entendimento sobre o trato com a disciplina na escola, propiciando a possibilidade do exercício da reflexão sobre a prática e estabelecendo relações com os conhecimentos advindos da formação inicial.

Assim, o professor-formador propôs a demonstração de uma vivência e o projeto que a originou, ou seja, a ação toma o sentido da experiência vivida de um plano de estágio desenvolvido em escola da educação básica, no qual os licenciandos assumiram o papel dos alunos da escola e o formador o papel do professor de Educação Física. Essa fase foi desenvolvida em 12 (doze) aulas de cinquenta minutos, ou seja, em três semanas, e organizada em três etapas:

$\mathbf{1}^{\mathrm{a}}$ etapa: realizada na primeira semana, com quatro aulas de duração, em que o formador abordou temas e conteúdos relacionados ao conhecimento sobre o corpo. Para tanto, os licenciandos participaram de vivências corporais que propiciassem a percepção de que "a intensidade do esforço influencia a frequência cardiorrespiratória" (tema da sequência de ensino). Esta ação formativa foi desenvolvida a partir de uma trajetória de ensino com onze situações propostas e previam experiência corporal, análise das ações realizadas, discussão e produção de conhecimentos a respeito do tema, apresentação dos resultados para a classe e avaliação. Desta forma, a primeira estratégia utilizada foi a de mostrar para os licenciandos uma concepção de ensino, para que, em um segundo momento, eles construíssem suas próprias sequências de aulas. A proposta apresentada incluía três outros temas que dariam continuidade ao plano de ensino do formador (Problemas corporais causados pelo excesso de esforço físico; Trabalho realizado pelo aparelho circulatório e aparelho respiratório durante a atividade física; Outros fatores que alteram os batimentos cardíacos), porém, não foram desenvolvidos nesse momento, mas seriam propostos como atividades da terceira etapa.

$2^{\mathbf{a}}$ etapa: realizada na semana seguinte, também com duração de quatro aulas. O formador apresentou aos licenciandos o plano de ensino utilizado na modelagem e os princípios adotados para tal. Tais princípios, apresentados a seguir, deveriam compor os planos de ensino que seriam posteriormente elaborados pelos licenciandos. 
- Dimensões do conteúdo: conceitos, procedimentos e atitudes. Ações previstas que considerassem como conteúdo não somente a atividade corporal, mas também outros extraídos na forma de conceitos ou possíveis mudanças atitudinais relacionadas aos objetivos propostos para tal. Nesse sentido, os conteúdos propostos para os alunos operacionalizam os objetivos de trabalho do futuro professor que necessitam ter coerência.

- Trajetória de Aprendizagem: experiências pensadas em função da descrição de um percurso que levará o aluno a desenvolver determinados conteúdos e aprender novos conceitos.

- Sequência e continuidade: as atividades propostas devem apresentar-se segundo uma lógica de pensamento, não sendo nem estanques e nem tampouco fragmentadas e, ainda, serem trabalhadas a partir de uma coerência em que a atividade seguinte dá continuidade a anterior.

- Tematização dos elementos da Cultura Corporal de Movimento: pressupõe a superação da visão de Educação Física como sinônima de atividade não séria, desempenho técnico e desenvolvimento físico. $\mathrm{O}$ trabalho proposto a partir de temas pressupõe a realização de uma ação pedagógica com essa cultura, pois considera a Educação Física como problematizadora dos elementos da Cultura Corporal de Movimento, devido à abrangência da área e à multiplicidade de fatores que envolvem e qualificam os seus diversos conhecimentos.

A opção em se trabalhar com a tematização desses elementos da cultura se dá pelo fato de que a Educação Física, ao longo do tempo, desenvolveu-se segundo uma concepção bastante criticada na atualidade. Em contraposição, a Cultura Corporal de Movimento, entendida como um elo integrador de diversas tendências surgidas a partir década de 1980, se apresenta como um ponto de convergência do pensamento contemporâneo em torno da área, mesmo quando tratada a partir de diferentes concepções e nomenclaturas (BETTI, 1991; COLETIVO DE AUTORES, 1992; KUNZ, 1994). Essas práticas têm sido apresentadas como um grande potencial transformador e crítico em relação ao movimento humano e, atualmente, muitos projetos com essas características começam efetivamente a se desenvolver como práticas concretas nos currículos escolares, apresentadas e publicadas em revistas da área. Nesse sentido, utilizamos como balizadora desse trabalho o conceito apresentado por Betti (2001) que a qualifica como Cultura Corporal de Movimento e a define como:

(...) parcela da cultura geral que abrange as formas culturais que se vêm historicamente construindo, nos planos material e simbólico, mediante o exercício (em geral sistemático e intencionado) da motricidade humana - jogo, esporte, ginásticas e práticas de aptidão física, atividades rítmicas/expressivas e dança, lutas/artes marciais, práticas corporais alternativas (BETTI, 2001, p.2).

$3^{\mathbf{a}}$ etapa: realizada na semana seguinte, com duração de quatro aulas. A ação previa a organização dos licenciandos para darem continuidade aos três temas propostos no 
plano de ensino do formador-pesquisador, desenvolvendo sequências de atividades para serem apresentadas no final da aula. Esta etapa foi utilizada para que eles refletissem sobre a ação já realizada e construíssem um novo conhecimento a partir das suas experiências. Também, como um espaço de reflexão no qual diferentes concepções e entendimentos se confrontassem em função da resolução do problema proposto. O resultado foi compartilhado na semana seguinte.

Como citado anteriormente por Schön (2000), foi um convite ao experimento, em que se solicitou aos licenciandos que seguissem os princípios do modelo de ensino proposto e, para tal, construíssem, em grupo, as características essenciais da demonstração.

\section{3ªção: Orientação e problematização de planos de ensino}

Ao final da ação formativa de modelagem, os licenciandos iniciaram a elaboração de seus planos de ensino para o estágio na Educação Infantil e nos anos iniciais do Ensino Fundamental (Prática Pedagógica III) sob a orientação do professor-formador, e segundo os princípios do modelo proposto. Para tal, era necessário que eles estivessem frequentando as escolas, campo de estágio, participando das aulas de forma compartilhada com o professor de Educação Física e realizado as atividades de observação de aulas.

O processo de elaboração dos planos de ensino foi feito fora do horário regular de aulas da faculdade e encaminhado para o professor-formador por meio eletrônico (e-mail). Após avaliação por parte deste, segundo os critérios elencados para a elaboração dos mesmos (vide categorias descritas na etapa 2 da segunda ação formativa), os planos foram devolvidos, também por e-mail, no prazo máximo de uma semana, com sugestões de correção quando necessário. Para a análise e correção dos planos de ensino, o formador adotou estratégias de questionamento (vide questões na $1^{\mathrm{a}}$ ação formativa) visando que os licenciandos refletissem sobre as propostas por eles elaboradas. Caso houvesse necessidade, o procedimento seria repetido.

\section{Apresentação e Discussão de Resultados}

Como anteriormente mencionado, nossos resultados buscam revelar contribuições decorrentes de três ações formativas desenvolvidas em disciplinas de Prática Pedagógica para a docência inicial em Educação Física, segundo depoimentos de futuros professores a elas submetidos.

Com relação à primeira ação, formação do professor reflexivo, a experiência nos revelou que o licenciando precisa ser orientado a planejar e pensar sobre as próprias ações propostas para que tenha consciência das mesmas. Talvez tenha sido este o motivo pelo qual grande parte dos licenciandos percebeu a ação formativa como fundamental para a sua aprendizagem prática, como nos mostram os depoimentos a seguir: 


\begin{abstract}
"Até mesmo na elaboração do projeto, a cada resposta que você dava, a gente pensava ai meu Deus o que fazer agora? Mas você fazia com que a gente pensasse mais, em como seria desmembrado, na organização didática, como fazer para chegar em tal coisa". (Kátia Gl)

“Esse ano você chegou e puxou isso, nos mostrando que tinha que ter essa forma e você nos mostrava isso nas trocas de e-mail, perguntando, por que você vai fazer isso? Por que dessa forma? Por que você vai fazer essa brincadeira? Qual o fundamento dela? Isso nos fazia pensar e mudar a forma de fazer. Isso a gente não teve muito. Várias situações e aprendizagens; esse ano foi totalmente diferente". (Alessandra GI)
\end{abstract}

Aprender fazendo, essa é a proposta da licencianda para a superação dos seus problemas. Desenvolver um diálogo reflexivo com a própria prática, com aquilo que você faz e observa de si mesmo, possibilitando a mudança no seu conhecimento e na sua ação. Em função do outro, eu me transformo. Nessa relação constituem-se novas atitudes que serão solicitadas no decorrer da profissão. Kátia (GII) indica a responsabilidade assumida pelo futuro profissional como uma atitude desenvolvida a partir da sua experiência no estágio:

\begin{abstract}
“Acho que é essa questão mesmo, da responsabilidade, de você passar a pensar mais na aula, eu tenho que procurar... eu tenho que me preparar muito para chegar lá e tentar ensinar alguma coisa para os alunos. É que antes ficava na brincadeira. Agora, com a proposta tem um sentido, até para explicar para eles. Antes a gente tentava falar alguma coisa, mas ficava naquilo mesmo: Educação Física tem que ser na quadra. Fico imaginando se não fosse o estágio, como eu faria para chegar à escola e dar aula. Sabe, tem professores mais velhos de cadeira que chegam e jogam a bola, será que se não fosse essa experiência não seríamos assim?" (Kátia GIl)
\end{abstract}

Muito embora a licencianda relate a sua dificuldade na realização da proposta apresentada para o estágio supervisionado, ela valoriza a existência de uma diretriz para seguir, para se guiar, na qual, o foco do trabalho deixa de ser apenas voltado ao movimento descontextualizado e passa a ser pensado em função da aprendizagem do aluno, ou seja, o ensino torna-se intencional, o estagiário tem alguma coisa para ensinar e assume a responsabilidade de fazê-lo, enquanto que o aluno tem algo a aprender.

Daise e Vilma, ambas do Gll, apontam uma condição de ver além do momento, uma nova situação proposta e desenvolvida por elas ao longo do estágio. Em outras palavras, se projetar, antecipar uma ação, se situar melhor, são ações que a prática apresenta ao profissional como uma condição para se organizar melhor para uma ação.

"Até onde vai chegar, mesmo que não atinja o objetivo, você sabe o que quer e para onde vai. Antes a gente ia para completar a carga horária. Isso aconteceu comigo agora no ensino fundamental e médio, quando a gente ia, já sabia o que fazer, como fazer, e isso foi importante, isso mudou muito, porque o ano passado a gente não tinha nada disso, nesse ponto eu acho que, prá mim ficou bem mais definido, desenvolvemos muito". (Daise GIl) 


\begin{abstract}
“Porque antes a gente focava o nosso projeto no movimento, a gente não pensava em outras coisas, simplesmente a gente trabalhava com o movimento. Não tinha bem focado que isso que é a Educação Física. A gente pode trabalhar muitas outras coisas, mas a gente não conseguia enxergar, os objetivos eram ocultos. Agora, nas nossas últimas aulas a gente conseguiu observar outras coisas que estão muito mais perto dos objetivos da escola e isso no ano passado não estava muito claro para nós. (...) Isso não estava muito focado na nossa cabeça, a gente ia ali dava as nossas aulas, não sabíamos o objetivo que queríamos alcançar". (Vilma GII)
\end{abstract}

Por sua vez, com relação à segunda ação formativa - demonstração de modelo de ensino (modelagem), a construção de sentido se processou a partir da interação do conhecido com o "novo" vivido. Essa relação é percebida na citação de Cláudia (GI), ao se referir à atividade de apresentação do modelo de ensino, demonstrando a importância para sua aprendizagem no processo desenvolvido no estágio.

"Foi importante também aquele início do trabalho, que nós fizemos a atividade
na quadra sobre frequência cardíaca, vivenciamos na prática, depois o trabalho
teórico, em seguida você [formador] perguntou: "E aí, vai parar aí?". Aí nós percebe-
mos... é verdade, não pode parar aí! Então nós fomos para a sala, fizemos o gráfico
e continuamos a aula. Nós percebemos que não era só aquilo. Nesse momento
é que nós começamos a verificar mesmo que houve uma mudança. Como você
vê aquilo? Como proceder? Clareou mas dificultou! Porque você falava que tinha
que refletir com os alunos e a gente não tinha como fazer, a gente não tinha essa
vivência. Aí, quando nós fizemos aquela vivência, deu para entender o que você
falava". (Cláudia GI)

Na sua fala, assegura a importância de um trabalho que propicie ao licenciando a condição de experimentar, na condição de aluno da escola, para daí compreender como as novas propostas podem ser implementadas na prática pedagógica do profissional, nesse caso, do estagiário, utilizando como exemplo que ilustraria a sua atividade de elaboração e desenvolvimento do plano de estágio. Essa sensação também é referenciada por outros integrantes da pesquisa.

“Você chegou lá e fez diferente... (...) como é isso então? (...) Lá eu pude ver e relacionar com o que você vinha falando. Na Prática Pedagógica, você foi explicando melhor como fazer as coisas e eu comecei a compreender melhor". (Mônica - GIII)

O conteúdo "vivo" possibilitado pela modelagem mostrou-se com potencial para ilustrar o que o conhecimento "das palavras" não possibilitou de forma isolada, ou seja, o sentido se construiu pela demonstração, vivência, conhecimentos prévios, palavras e pela reconstrução/reorganização do pensamento.

É a linguagem da ação permeada pela reflexão daqueles que se envolvem diretamente com a experiência, e valorosa para a sua compreensão. A esse respeito, Pérez-Gómez (1992) afirma que a reflexão "não é um conhecimento 'puro', mas, sim, um conhecimento contaminado pelas contingências que rodeiam e impregnam a própria experiência vital" 
(p.103). Ou seja, o contexto em que se realiza a reflexão o ajuda a interpretar a realidade e, sendo assim, torna-se um conhecimento contextualizado "da" e "na" própria experiência. A reflexão possibilita a condição de antecipar uma ação futura, de antever situações, de projetar-se, permitindo aos futuros profissionais a condição de planejar as atividades em função do contexto de sua aplicação. De acordo com as transcrições das falas dos licenciandos, somente foi possível interpretar aquela realidade quando pararam para refletir sobre as suas próprias impressões sobre o que haviam experimentado em um determinado contexto. O sentido literal de refletir refere-se a uma condição de perceber qual é o reflexo, a imagem formada, as representações extraídas de determinados atos, palavras, situações, experimentos e o seu resultado direto. Diante disso, não é no momento exato em que me envolvo com determinada ação que reconstruo meu conhecimento, mas sim, no momento seguinte, quando paro e me ponho a pensar, analisar e refletir sobre o vivido, o realizado.

A situação descrita pelos entrevistados sobre as experiências obtidas a partir da atividade de apresentação do modelo de ensino do formador é citada por Alarcão (1996) como uma estratégia de ação, e entendida por Schön (2000) como demonstração acompanhada de reflexão; é o siga-me (follow me).

Esta estratégia em vez de ser vista em termos de "o formador demonstra; o formando imita", tem de ser considerada como "o formador demonstra, descreve o que demonstra, reflete sobre o que faz e o que descreve. De igual modo procede o formando, ao interrogar-se sobre o sentido da acção observada e descrita" (ALARCÃO, 1996, p.20 - grifos do autor).

As atividades propostas aos alunos seguiram a estratégia descrita pela autora, uma vez que a demonstração do formador foi seguida por um processo de descrição das ações, no qual ele apresentou o plano de ensino proposto para aquela aula vivida pelos licenciandos. Em seguida, procedeu-se a reflexão coletiva sobre a ação, para, em sequência, o formando interrogar-se sobre o sentido daquela ação, contrastando as suas antigas concepções/convicções com as recém constituídas a partir do novo modelo apresentado, e que seriam utilizadas nas suas atividades de estágio.

Laura e Paula (ambas do GI) ressaltaram o fato de que as ações formativas possibilitaram a organização do estágio, tanto em termos de elaboração, quanto na questão da sequência, o que demonstra a mudança no trabalho desenvolvido nos estágios anteriores que, segundo seus depoimentos, não previa a antecipação das ações. As regências eram inicialmente pensadas em função do momento, sem expectativas de aprendizagem.

"Antes era muito diferente... A gente chegou no terceiro ano e mudou totalmente a forma de fazer, porque no segundo ano a gente ia lá enfrentava a aula e depois anotava o que tinha feito. No terceiro ano, a gente tinha que pensar o projeto e depois ir lá desenvolver e isso ficou mais difícil". (Laura GI)

“Eu fui para o estágio e a cada dia eu percebia que aquilo estava dando certo, eu sabia o que fazer, ia com segurança, mas, tudo isso começou no projeto, quando você começou a me perguntar sobre as coisas que eu tinha escrito". (Paula Gl) 
Os procedimentos adotados para a construção do plano de ensino para o estágio também foram apontados pelos licenciandos como de grande contribuição para o desenvolvimento das suas ações. Para eles significou uma experiência diferente, até porque foi realizada em outro momento da formação e, portanto, em outro contexto. Todo esse processo foi mediado pela interlocução dos licenciandos com o formador. O objetivo principal dessa ação foi o de promover a mudança interna no futuro profissional, partindo da reflexão sobre seus próprios atos, agregando novos conhecimentos àqueles já internalizados por ele.

"O plano de ensino. A partir das correções, das suas análises, eu fui vendo, conversando com os colegas, fui correndo atrás, pedindo ajuda para colocar as aulas certinhas. Eu acho que aí eu consegui montar o plano. E por isso eu acho que hoje está mais fácil”. (Mônica GIII)

Por isso, o processo de orientação que se desenvolveu em formato eletrônico, por e-mail, foi apontado como uma experiência bastante significativa para os licenciandos. Estes relatam sobre a importância do formador ter apontado as lacunas e os detalhes ainda não percebidos por eles. Devido à complexidade do processo de aprendizagem do novo, eles chamam atenção para a necessidade do formador estar atento a vieses em relação à compreensão do vivido, uma vez que, embora os procedimentos utilizados fossem sempre coletivos, o resultado de cada ação era individual. Ao contrastar novas proposições com as concepções já construídas e internalizadas, cada licenciando a interpreta de uma forma, visto que, pressupõe um posicionamento pessoal/situacional. Isso implica que a construção seja coletiva, mas, ao mesmo tempo, acompanhada de orientação individual que, nesse processo, ocorreu a partir de formato eletrônico (e-mail). Em suas falas, deixaram transparecer a complexidade do procedimento de elaboração das propostas de ação para o seu desenvolvimento posterior, mas também, que quando estavam prontas, ficava mais fácil para trabalhar. Assim, o papel do formador é muito maior do que apenas demonstrar, orientar e corrigir planos. Suas ações, gestos e palavras levam o licenciando a perceber e compreender como, porque e quando determinadas estratégias podem ser utilizadas. Entender o processo como um todo é muito mais importante do que reproduzir modelos prontos. Para Laura, essa experiência lhe propiciou um crescimento substancial.

\footnotetext{
"'Crescimento'. No sentido da gente mandar primeiro as primeiras questões, as primeiras aulas e você mandar dizendo que não é bem por esse lado, não é assim, explica melhor, dá cada passo... Então, primeiro a gente não dava passo a passo do que a gente queria fazer. Começamos a melhorar e ficou até mais fácil chegar na escola, por que nós não ficávamos perdidos, às vezes faltavam quinze minutos para acabar a aula, mas sabíamos que ainda tinha coisa para fazer, então ficou mais fácil para organizar, eu acredito que do primeiro estágio que desenvolvi para esse ficou mais fácil". (Laura Gl)
}

O crescimento atestado pela licencianda está relacionado à condição de se organizar melhor para as ações, saber o que, como e porque fazer aquilo que estava sendo 
proposto, ou seja, executar as ações de forma consciente. Sua dificuldade inicial referia-se ao planejamento dos futuros passos, ao desenvolvimento da condição de imaginar uma situação antes da sua realização, conseguir planejar aquilo que iria ensinar para os alunos. Isso é comum no processo de formação inicial, pois devido à falta de experiência, vivência e trabalho nessa função de professor, eles têm dificuldade para se organizar frente ao imprevisto, ao desconhecido. Isso também nos leva, mais uma vez, a reforçar a necessidade da formação de professores ampliar os espaços de convivência com a prática profissional.

Ao citar a palavra passos, Laura se referia à trajetória que deveria ser descrita no seu plano de ensino para o estágio. É um item do projeto que, segundo a aluna, quando está bem claro, facilita o desenvolvimento das suas ações. Nessa proposta os alunos descreveram o percurso, a trajetória de trabalho pensada em ações que seriam necessárias para o alcance dos objetivos propostos, e não, seguindo o formato tradicional dos planos de aula. As ações eram previstas para serem desenvolvidas em aproximadamente 10 aulas e asseguravam sempre sequência e continuidade com a próxima. Assim, se chegasse ao final de uma atividade prevista para aquele dia e ainda houvesse tempo de aula, poderia ser iniciada a próxima ação, dando continuidade na próxima aula.

O processo de construção do plano de ensino para o estágio e referendado pelos entrevistados propicia aos licenciandos a condição de passar pela experiência e recriá-la à luz dos conhecimentos já constituídos e das novas relações estabelecidas em função do contexto em que se desenvolve. Propor a sua estratégia de ação e testá-la à luz daquilo que foi inicialmente experimentado, agora, de forma diferente do já realizado. Essa ação pressupõe ao licenciando "externar" o que está "interiorizado".

Em primeiro lugar, um instrutor pode ajudar a estudante a descobrir como ela concebeu uma função ou um problema, na prática, mostrando de que forma ela os recriou na aula prática. A estudante pode agora ver em outros, olhando de fora, o que já havia experimentado do lado de dentro... Sua consciência de modo como já concebeu uma função ou problema prepara-a para a tarefa de entrar em uma nova maneira de fazê-lo. (SCHÖN, 2000, p.186).

Desta forma, a ação proposta possibilitou que os licenciandos delineassem um processo de "internalização" de um novo conhecimento agregado ao anterior a partir da aproximação do conhecido ao novo e, externá-lo novamente em outra situação.

O processo de elaboração dos planos de estágio serve também como um espaço de reflexão sobre-a-ação. Porém, para que isso seja possível, o trabalho de orientação realizado pelo formador deve pressupor ao licenciando um espaço de análise da ação proposta, na qual as suas convicções são colocadas à prova pelo "modelo" apresentado. A experiência promovida pelas ações formativas originou novos planos de ensino, objeto de análise pelo formador e devolução de pontos de reflexão sobre as ações propostas. Segundo o relato a seguir, essas ações teriam grande potencial para gerar novos conhecimentos aos licenciandos. 


\begin{abstract}
"Eu acho que o grande ponto mesmo foi essa troca e você deixar meio que no ar assim pra gente, não que deixou a desejar, mas de não ter falado tem que fazer dessa forma, mas assim, tentar melhorar, tem que ir por tal lado, vai por ali, e deixar assim meio para a gente pensar, se iria dar certo, será que a coisa é por ali? Como pode ser então? Será que a coisa vai funcionar?" (Kátia GI)
\end{abstract}

Para a entrevistada, o formato da orientação faz toda a diferença. A orientação, problematização e correção dos planos de estágio têm o papel de levar o licenciando a pensar sobre suas propostas de ação. Para isso, as devolutivas do formador têm que ser questionadoras das ações trazidas no plano de ensino, possibilitando novas reflexões que dêem vazão a outras ideias, ampliando os seus conhecimentos a partir de novas experiências. Assim, o pensamento é a ação desencadeadora de novas experiências. Segundo Dewey (1936, p.196), "pelo pensamento nós prevemos as consequências (sic)". Isso pressupõe que o pensamento é a condição necessária para a organização de uma ação. Ainda, para o autor, "a antevisão de consequências significa uma solução proposta ou tentada. Para se aperfeiçoar esta hypothese, devem ser cuidadosamente analysados as condições existentes e o conteúdo da hypothese adotada - acto que se chama raciocínio (sic) (p.196).

Os licenciandos entenderam que o formato das estratégias utilizadas nas aulas propiciou mudanças significativas na forma de apresentação da Educação Física, organização e desenvolvimento dos planos de estágio. Isto, devido à necessidade de se prever com antecedência as ações para serem realizadas no estágio.

O planejamento da ação construído a partir do pensamento e o seu desenvolvimento possibilitam a associação retrospectiva e prospectiva daquilo que projetamos e fizemos e as consequencias advindas dos nossos atos ou ações, o que Dewey (1936) concebe como "aprender da experiência". Para o referido autor, esse tipo de ação torna-se uma tentativa: "experimenta-se o mundo para se saber como elle é; o que se soffrer em consequencia torna-se instrução - isto é, a descoberta das relações entre as cousas (sic)" (p.182). De certa forma, não há experiência desprovida de sentido, visto que, para cada ação há uma reação. O valor da ação está no sentido e no sem sentido que se constrói sobre ela.

Outro dado importante é que os licenciandos julgam que o modelo de ensino, com base na tematização da Cultura Corporal de Movimento e na reflexão docente, apoiados pela orientação, problematização e replanejamento dos seus planos de estágio, possibilitou-lhes uma prática diferenciada, que foi reconhecida e valorizada por parte dos integrantes das escolas nas quais estagiaram.

\title{
CONSIDERAÇÕES FINAIS
}

Nesta pesquisa, contribuições significativas promovidas pelas três ações formativas desenvolvidas nos componentes curriculares da Prática Pedagógica foram identificadas: a atividade de modelagem se apresentou como um grande potencial de aprendizagem para os futuros professores, muito embora a experiência do licenciando não possa se esgotar 
na vivência corporal. Esta precisa ser acompanhada de reflexões que o levem a questionar suas concepções para, em seguida, propor uma ação de intervenção. Todo esse processo foi mediado pelo formador, que é o responsável por apresentar críticas ao plano de ensino proposto, apresentando alternativas práticas e viáveis, visto que não basta a crítica. Para a realização dessa tarefa, o formador precisa ter vasta experiência na área escolar para poder transitar nesse âmbito e corrigir os descaminhos que possam surgir nos planos de ação propostos pelos licenciandos, bem como nos momentos de reflexão individuais e coletivos sobre tais planos.

Todo esse processo foi permeado pela reflexão que também acompanha o licenciando no desenvolvimento do seu plano de ação. É nesse momento que os conhecimentos são colocados à prova e ele tem condição de perceber se o proposto pode se configurar em ação concreta. Essas ações são objeto de reflexão e reconfiguração, gerando novas práticas. Nesse processo de ir e vir, o conhecimento vai se transformando e, gradativamente, o estagiário vai construindo novos saberes que contribuem para a sua futura atuação de professor de Educação Física.

Finalmente, não pretendemos sugerir que as ações formativas descritas neste trabalho sejam compreendidas como um modelo de formação para disciplinas de Prática Pedagógica, mas, sim, enfatizar que tais componentes curriculares precisam ser concebidos como espaços de (re) significações de novas teorias e práticas pelos futuros profissionais, com o propósito de que possam desenvolver experiências inovadoras. Nesse sentido, nossos resultados apontam que ações mediadas pelo formador e suas interlocuções com os licenciandos constituem o conteúdo sobre o qual se impõe a necessidade de um processo reflexivo por parte de ambos. Tais ações formativas, desenvolvidas nos componentes curriculares de Prática Pedagógica, com o objetivo de estudar, debater e colocar o licenciando em contato com a futura profissão, tem um grande potencial para articular experiências com o estágio supervisionado, promovendo novas vivências significativas aos futuros professores de Educação Física.

\section{REFERÊNCIAS}

ALARCÃO, I. Formação Reflexiva de Professores: estratégias de supervisão. Porto: Porto Editora, 1996.

BETTI, M. M. Educação Física e sociedade. São Paulo: Movimento, 1991. Imagem e ação: a televisão e a Educação Física escolar. Bauru: Relatório final de pesquisa apresentado à Fundação para o Desenvolvimento da UNESP, 2001.

CHAVES, S. N. A construção coletiva de uma prática de formação de professores de ciências: tensões entre o pensar e o agir. Tese de Doutorado. Faculdade de Educação. UNICAMP, Campinas, 2000.

COLETIVO DE AUTORES. Metodologia do ensino da educação física. São Paulo: Cortez, 1992.

DEWEY, J. Democracia e Educação: breve tratado de Philosofia da Educação. São Paulo: Companhia Editora Nacional, 1936. 
KUNZ, E. Transformação didático-pedagógica do esporte. ljuí: Unijuí, 1994.

LÜDKE, M.; ANDRÉ. M.E.D.A. Pesquisa em Educação: abordagens qualitativas. São Paulo: EPU, 1986.

MALDANER, O. A. A formação Inicial e Continuada de Professores de Química Professores/Pesquisadores. Ijuí Ed. Unijuí. 2000. 424p. (Coleção Educação em Química).

MARCELO, C. G. A formação de professores: Centro de atenção e pedra de toque. In: NÓVOA, A. (org.) Os professores e sua formação. Lisboa: Dom Quixote, 1992.

PÉREZ-GÓMEZ, A. O pensamento prático do professor: a formação do professor como profissional reflexivo. In: Nóvoa, A. (org.) Os professores e sua formação. Lisboa: Dom Quixote, 1992.

PIMENTA, Selma Garrido. O estágio na formação de professores: unidade teoria e prática? 4. ed. São Paulo: Cortez, 2001.

SCHNETZLER, R.P. O PROFESSOR DE CIÊNCIAS: problemas e tendências de sua formação. In. SCHNETZLER, R.P \& ARAGÃO, R.M.R. (Orgs.). ENSINO DE CIÊNCIAS: fundamentos e abordagens. CAPES/UNIMEP, 2000.

SCHNETZLER, R.P. A pesquisa em ensino de química no Brasil: conquistas e perspectivas. Química Nova, supl.1, p. 14-24, 2002.

SCHÖN, D.A. Formar professores como profissionais reflexivos. In: A. Nóvoa (Ed.). Os professores e a sua formação. Lisboa: Dom Quichote, 1992.

Educando o profissional reflexivo: um novo design para o ensino e a aprendizagem/ Donald A. Schön; trad. Roberto Cataldo Costa - Porto Alegre: Artes Médicas Sul, 2000.

ZEICHNER, K. M., A Formação Reflexiva de Professores: Idéias e Práticas. Lisboa: Educa, 1993. 